\title{
Article \\ Enhanced Performance of Immobilized Rhizopus oryzae Lipase on Coated Porous Polypropylene Support with Additives
}

\author{
Fatimah Sani ${ }^{1}$ (D), Nur Fathiah Mokhtar ${ }^{1}$, Mohd Shukuri Mohamad Ali ${ }^{1,2}$ \\ and Raja Noor Zaliha Raja Abd Rahman 1,2,3,4,*(D)
}

1 Enzyme and Microbial Technology Research Centre (EMTech), Faculty of Biotechnology and Biomolecular Science, Universiti Putra Malaysia, Serdang 43400, Selangor, Malaysia; fatimahsani@yahoo.com (F.S.); nurfathiah93@gmail.com (N.F.M.); mshukuri@upm.edu.my (M.S.M.A.)

2 Department of Biochemistry, Faculty of Biotechnology and Biomolecular Science, Universiti Putra Malaysia, Serdang 43400, Selangor, Malaysia

3 Department of Microbiology, Faculty of Biotechnology and Biomolecular Science, Universiti Putra Malaysia, Serdang 43400, Selangor, Malaysia

4 Institute of Bioscience, Universiti Putra Malaysia, Serdang 43400, Selangor, Malaysia

* Correspondence: rnzaliha@upm.edu.my

Citation: Sani, F.; Mokhtar, N.F.; Mohamad Ali, M.S.; Raja Abd Rahman, R.N.Z. Enhanced Performance of Immobilized Rhizopus oryzae Lipase on Coated Porous Polypropylene Support with Additives. Catalysts 2021, 11, 303. https://doi.org/10.3390/catal11030303

Academic Editor: Francisco Plou

Received: 26 January 2021

Accepted: 18 February 2021

Published: 26 February 2021

Publisher's Note: MDPI stays neutral with regard to jurisdictional claims in published maps and institutional affiliations.

Copyright: (c) 2021 by the authors. Licensee MDPI, Basel, Switzerland. This article is an open access article distributed under the terms and conditions of the Creative Commons Attribution (CC BY) license (https:// creativecommons.org/licenses/by/ $4.0 /)$.

\begin{abstract}
The immobilization of Rhizopus oryzae lipase (RoL) by hydrophobic adsorption on polypropylene supports with additives was investigated. Additives such as hen egg albumin, sodium caseinate and CAVAMAX ${ }^{\circledR}$ W6 were used to coat the support during immobilization where the immobilized RoL on coated support was compared to those of noncoated support. Following the immobilization, the catalytic activity of immobilized RoL was characterized based on different temperatures and $\mathrm{pH}$. The immobilized RoL without additives showed optimal lipase activity at an optimum temperature of $50{ }^{\circ} \mathrm{C}$ and $\mathrm{pH}$. However, RoL lipase that was immobilized on support treated with CAVAMAX ${ }^{\circledR}$ W6 had better performance in terms of hydrolytic activity and stability as compared to other additives. In addition, by having a support treated with hen egg albumin, the immobilized RoL was capable of yielding higher ester during esterification reactions.
\end{abstract}

Keywords: polypropylene; additive; Rhizopus oryzae; lipase

\section{Introduction}

Lipases (triacylglycerol hydrolases, EC 3.1.1.3) belong to the enzyme class of hydrolases catalyzing the hydrolysis of the triglycerides at the lipid water interface into fatty acids, mono- and diacylglycerols, and glycerol. In terms of application, lipases have been widely used in the food industry and have a highly selective reaction towards a wide range of substrates. Lipases with 1,3-positional selectivity play an essential role in synthesizing 1,3-diacylglycerol and structured lipids [1]. However, said lipases are highly unstable in an aqueous form, which requires immobilization to form immobilized lipase with enhanced activity, thermal, reusability, and operational stability. Various immobilization methods have been applied to lipase, such as adsorption, entrapment, covalent binding, and crosslinking in which the most applied method for lipase immobilization is physical adsorption. However, the interaction between support and lipase via physical adsorption is weak and prone to leaching out from the supports [2,3].

The immobilization of lipases on engineered supports could refrain the free movement of the lid or allow the enzyme to immobilize in an open form where the immobilized lipase remains active. The activation of Rhizopus oryzae lipase occurred when the condition of immobilization includes the hydrophobic surface of the support that displaces the lid, permitting the open conformation of lipase [4]. As the support becomes highly hydrophobic, the inner pores of the support turned out to be inaccessible to the aqueous enzyme solution. Most microbial enzymes have different pore sizes that ranged from 4 to $5 \mathrm{~nm}$. Hence, 
the size of the pore and porosity would contribute toward localization of enzyme on the support [5].

Polypropylene support is well known for adsorption of lipase and has been extensively utilized for the immobilization. For example, a locally purchased MP1008 is a porous polypropylene commercial support and had been used for immobilizing several lipases derived from Candida antarctica [6], Burkholderia cepacian [7], Mucor javanicus [8], Candida rugosa [9], Aspergillus niger, Mucor javanicus and Penicillium roqueforti (A, M and $\mathrm{R}$ lipase) [10]. In general, the support provides good immobilization performance due to its irregular shape, high hydrophobicity and porosity. As for applications, the support benefited industry in terms of a cost-saving approach that links to the preparation of biocatalyst and new applications [6]. However, there is also limitation on the utilization of readily available supports as the existing one contributes to the loss of hydrolytic activity of the immobilized Rhizopus oryzae lipase (rROL) [11].

Therefore, by coating support with additives, the interactions of the enzyme with the support can be improved and simultaneously enhance the lipase activity and stability. In addition, further loss of enzyme activity after immobilization can be avoided by adding additives during immobilization, affecting the microenvironment of the enzyme. According to [12], $\beta$-cyclodextrin has shown positive results in the biocatalytic activity of Yarrowia lipolytica Lipase 2 (YLLIP2) in organic solvents [12]. Undesirable interactions of similar-size or larger proteins with the support surface can be prevented using a medium-sized protein, bovine serum albumin, following the disclosure by Bolivar et al. [13], which eases the adsorption of smaller proteins on the support.

The use of immobilized lipases in non-aqueous reaction media is highly preferred over aqueous solutions for industrial application where a reverse reaction can be applied for biocatalysis. In the present study, the immobilized RoL was subjected to esterification on oleic acid to produce ethyl oleate. Ethyl oleate is a fatty ester commonly used as a fuel additive and as a solvent for pharmaceutical drug preparation. Therefore, this study aimed to investigate the effect of the additive coatings on the polypropylene support for the purpose of immobilizing Rhizopus oryzae lipase, where the difference of immobilized lipase on different additive supports was determined based on its activity and ability to perform esterification with high ester conversion.

\section{Results}

\subsection{Immobilization of RoL in Polypropylene Support}

The immobilization of RoL via adsorption technique in the presence of additives for surface coating polymers was studied. The additives used were hen egg albumin, sodium caseinate and CAVAMAX ${ }^{\circledR}$ W6, which were of food grade. Previously, hen egg albumin was used as an additive in the immobilization of RoL according to Bosley and Peilow, 1993 [14]. The effect of adding additives on the RoL immobilization on a polypropylene support was shown in Figure 1. Based on Figure 1, about 96\% of RoL lipase was adsorbed in the support treated with hen egg albumin, followed by $89 \%$ with CAVAMAX ${ }^{\circledR}$ W6 and $71 \%$ with sodium caseinate. As for untreated support, it was less than $10 \%$ of lipase being physically adsorbed.

Although hen egg albumin contributed towards high yield of RoL immobilization, a significant loss of $91 \%$ was observed in the hydrolytic activity of RoL after immobilization on the same supports with same additive (Table 1). As for supports treated with sodium caseinate and CAVAMAX ${ }^{\circledR} \mathrm{W} 6,43 \%$ and $51 \%$ of enzymes remained adsorbed to respective supports. It shows that the strong binding interaction between enzyme and the support via multiple attachments was obtained. 


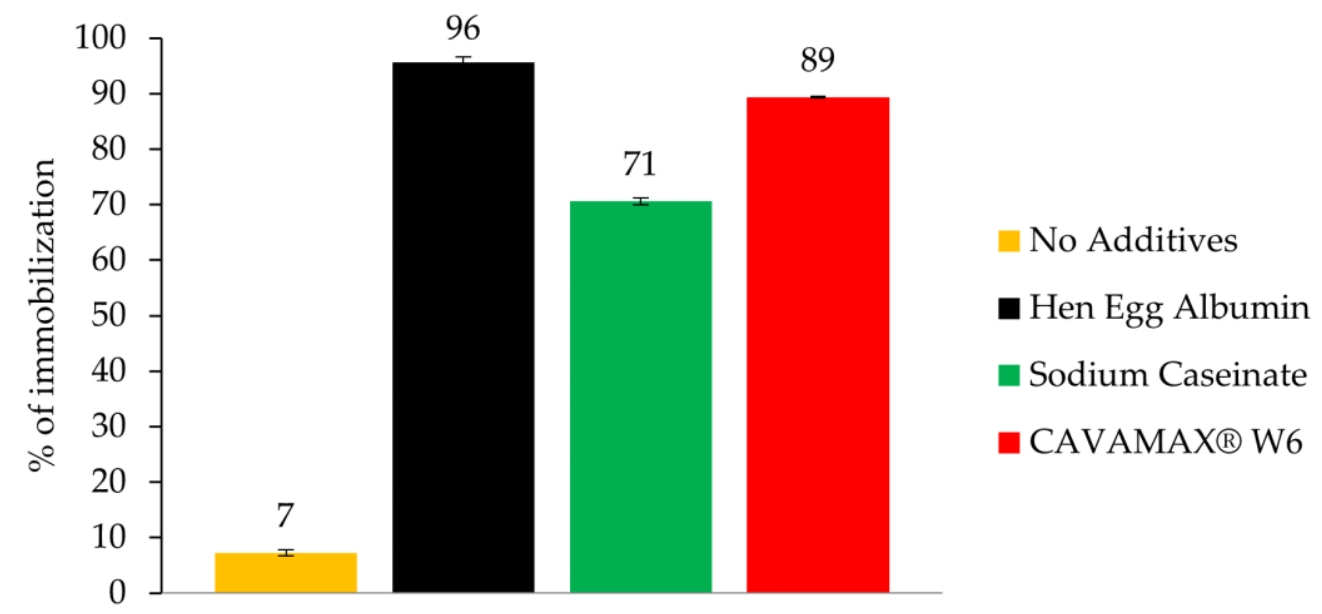

Pre-treatments

Figure 1. Immobilization yield of Rhizopus oryzae lipase (RoL) immobilized on no additives and additive-treated polypropylene support. Additives use in this study were hen egg albumin, sodium caseinate and CAVAMAX ${ }^{\circledR}$ W6. The measurement of yield of immobilization was conducted in triplicate and relative activities are measured as mean values \pm standard error.

Table 1. The percentage of enzyme leaching from immobilized RoL.

\begin{tabular}{cc}
\hline Supports/Treatments & Percentage of Loss after Immobilization (\%) \\
\hline No Additives & 0 \\
Hen egg albumin & 91 \\
Sodium caseinate & 43 \\
CAVAMAX ${ }^{\circledR}$ W6 & 51 \\
\hline
\end{tabular}

\subsection{Biocatalytic Properties of Immobilized RoL}

\subsubsection{Effect of Temperature on Lipase Activity}

According to Figure 2, the relative activity of free and immobilized RoL with the effect of various assay temperatures was determined and compared. The activity of RoL immobilized on support treated with hen egg albumin achieved the lowest activity at 20 to $30{ }^{\circ} \mathrm{C}$, while at 40 to $50{ }^{\circ} \mathrm{C}$, the relative activity of RoL increased up to $80 \%$ and $100 \%$, respectively. The immobilized lipase on CAVAMAX ${ }^{\circledR}$ W6 support attained the highest lipase activity followed by sodium caseinate at 435.7 and $311.8 \mathrm{U} / \mathrm{g}$, respectively. However, as the temperature increased to $60^{\circ} \mathrm{C}$, lipase activity of immobilized RoL with CAVAMAX ${ }^{\circledR}$ W6 support started to decline. Overall, more than $50 \%$ of the enzyme was lost when assayed at and beyond said temperature.

\subsubsection{Effect of Temperature on Lipase Stability}

For the analysis of thermal stability (Figure 3), incubation on free and immobilized RoL was performed at $50{ }^{\circ} \mathrm{C}$ and assayed on an hourly basis up to $6 \mathrm{~h}$. The relative activity of immobilized RoL appeared to decline gradually throughout $6 \mathrm{~h}$ of incubation. Accordingly, the half-life of free RoL was observed after $2 \mathrm{~h}$ of incubation, similar to the half-life of immobilized RoL on support without additives and immobilized RoL with hen egg albumin as the additive to the support. As for immobilized RoL on a support treated with sodium caseinate and CAVAMAX ${ }^{\circledR}$ W6 the half-life at $50{ }^{\circ} \mathrm{C}$ was found to be 5 and $6 \mathrm{~h}$, respectively. 


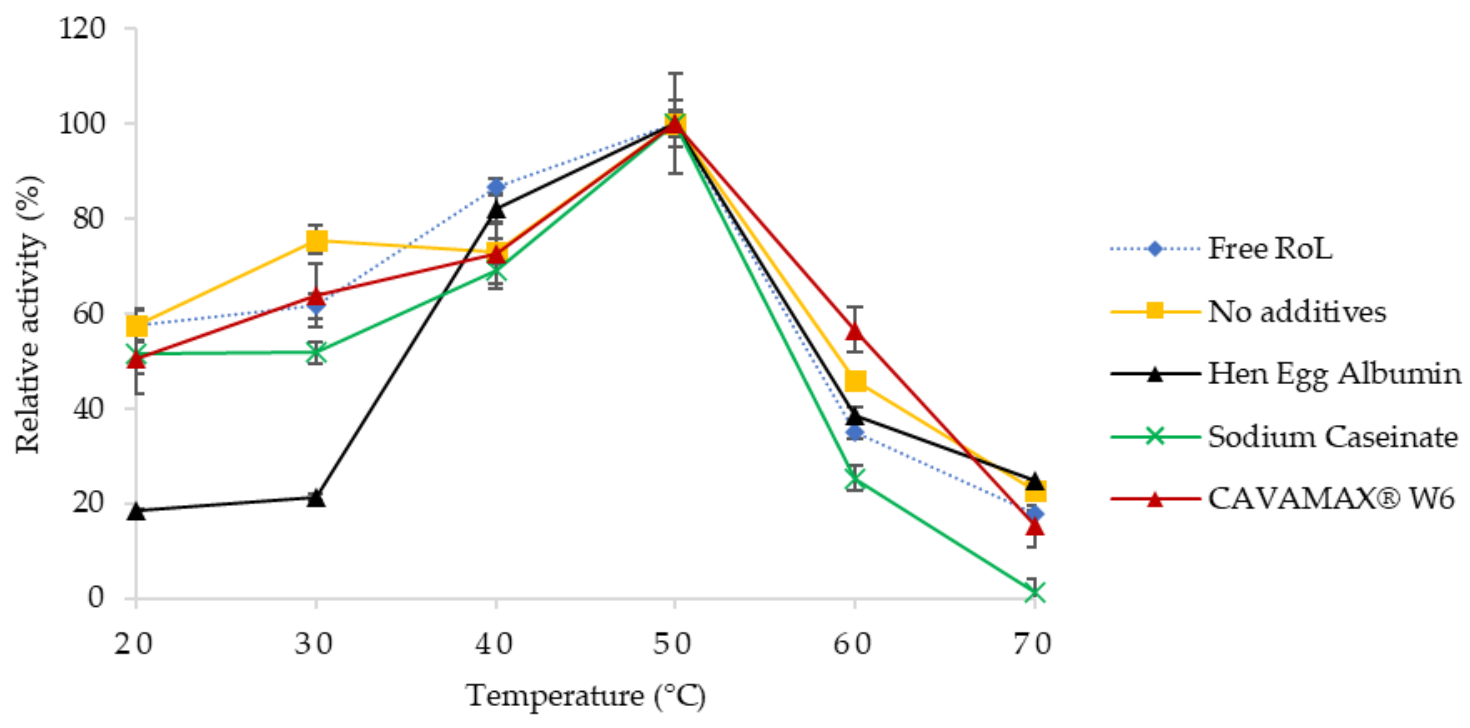

Figure 2. Temperature profile of free and immobilized RoL on polypropylene support with and without additives that include hen egg albumin, sodium caseinate and CAVAMAX ${ }^{\circledR}$ W6. The optimum temperature of immobilized RoL was measured at different temperatures ranging from 20 to $70{ }^{\circ} \mathrm{C}$. All measurements were carried out in triplicate and calculated as mean $\pm \operatorname{SE}(n=3)$.

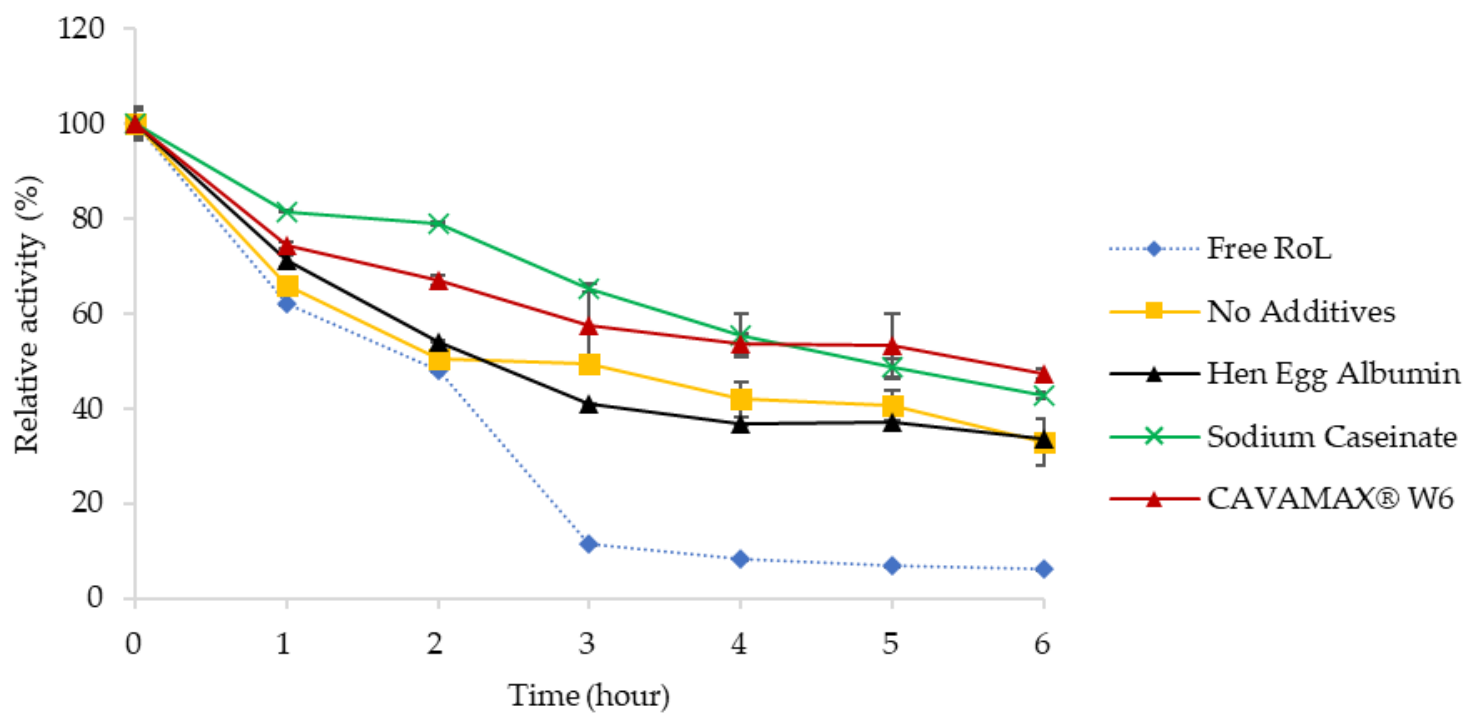

Figure 3. Thermal stability profile of free and immobilized RoL on polypropylene support with and without additives that include hen egg albumin, sodium caseinate and CAVAMAX ${ }^{\circledR}$ W6. The thermal stability of immobilized RoL was evaluated by incubating free and immobilized lipase at $50{ }^{\circ} \mathrm{C}$ in potassium phosphate buffer ( $\left.\mathrm{pH} 6.0\right)$ up to $6 \mathrm{~h}$. The relative enzyme activity was taken at $50{ }^{\circ} \mathrm{C}$ as $100 \%$ on the non-incubated lipase. All measurements were carried out in triplicate and calculated in mean $\pm \mathrm{SE}(\mathrm{n}=3)$.

The RoL immobilized on support with CAVAMAX ${ }^{\circledR}$ W6 exhibited $76 \%$ of remaining lipase activity when stored for 120 days at $4{ }^{\circ} \mathrm{C}$ (Figure 4A), while the half-life of similarly immobilized RoL was 60 days of storage at room temperature (Figure $4 \mathrm{~B}$ ). The half-life of immobilized RoL without additive at $4{ }^{\circ} \mathrm{C}$ storage was recorded at day 90 , similar to RoL immobilized on support with hen egg albumin stored at $4{ }^{\circ} \mathrm{C}$. However, the half-life of immobilized RoL without additives declined to less than 30 days when stored at room temperature. The RoL immobilized on support with sodium caseinate produced a half-life of 120 days at $4{ }^{\circ} \mathrm{C}$ and room temperature storage. After 120 days of storage, the free 
form of RoL exhibited a decrease in lipase activity to $30 \%$ and $15 \%$ at $4{ }^{\circ} \mathrm{C}$ and room temperature, respectively.
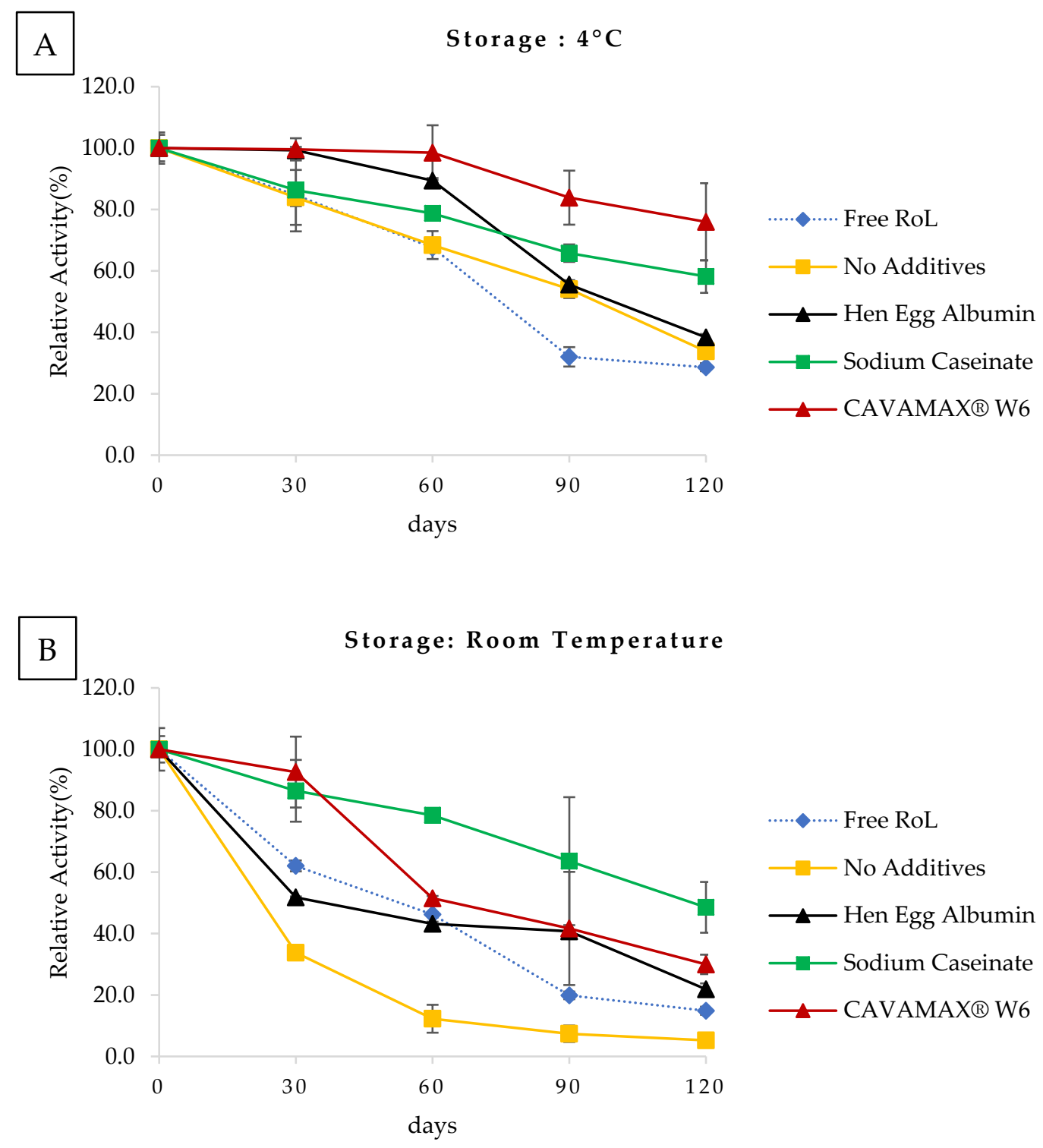

Figure 4. Storage stability of free and immobilized RoL on polypropylene support with and without additives that include hen egg albumin, sodium caseinate and CAVAMAX ${ }^{\circledR}$ W6. The data were a display of storage activity for 120 days in (A) $4{ }^{\circ} \mathrm{C}$ and (B) room temperature. The relative activity at 0 days of storage was referred to as $100 \%$. All measurements were carried out in triplicate and data were calculated in mean \pm SE $(n=3)$.

\subsubsection{Effect of $\mathrm{pH}$ on Lipase Activity}

The effect of $\mathrm{pH}$ on lipase activity of free and immobilized RoL was evaluated by an assay having a $\mathrm{pH}$ adjusted to a range of 4 to 9 using different types of buffer. According to Figure 5, both free and immobilized RoL were very stable at $\mathrm{pH} 4$ to 6 in which phosphate buffer gave the optimum $\mathrm{pH}$, which was $\mathrm{pH}$ 6. The highest activity was observed on RoL immobilized on support treated with sodium caseinate, which was $693.7 \mathrm{U} / \mathrm{g}$, followed by RoL immobilized on support coated with CAVAMAX ${ }^{\circledR}$ W6 which was $465.5 \mathrm{U} / \mathrm{g}$. In Tris- $\mathrm{HCl}$ buffer ( $\mathrm{pH} 8)$, the immobilized RoL was capable of producing lipase activity higher than $50 \%$. 


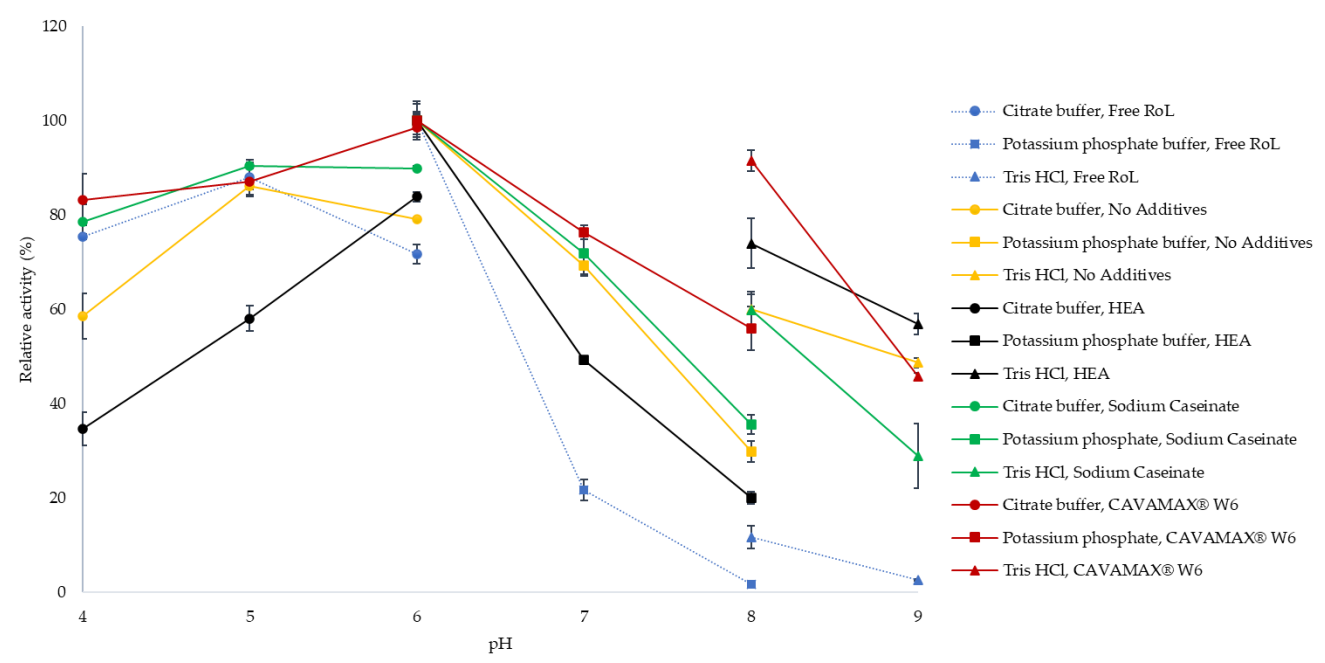

Figure 5. $\mathrm{pH}$ profile of free and immobilized RoL on polypropylene support with and without additives that include hen egg albumin, sodium caseinate and CAVAMAX ${ }^{\circledR}$ W6. Optimum pH was determined based on the activity of free and immobilized RoL at various $\mathrm{pH}$ comprising (•) $50 \mathrm{mM}$ sodium citrate buffer ( $\mathrm{pH} 4-5),(\boldsymbol{\square}) 50 \mathrm{mM}$ potassium phosphate buffer ( $\mathrm{pH}$ 6-8) and ( $\mathbf{\Lambda}) 50 \mathrm{mM}$ Tris- $\mathrm{HCl}$ buffer ( $\mathrm{pH}$ 8-9). The relative activity at different $\mathrm{pH}$ values was calculated by setting the optimum $\mathrm{pH}$ as $100 \%$. All measurements were carried out in triplicate and data were calculated in mean $\pm \mathrm{SE}$ $(n=3)$.

\subsection{Scanning of Electron Microscopy (SEM)}

SEM micrographs as disclosed in Figure 6 revealed the morphology of polypropylene supports having pores structure of nonuniform size. Accordingly, the difference in the size of the particle of the support on the reference of before and after immobilization was found to be between 1.131-1.910 $\mathrm{mm}$. The morphology of the support was also reported to be similar to Silva et al. 2015. After immobilizing RoL on treated support, the area of porosity became less obvious (Figure 6G-I). This indicates that the void areas inside the pores are filled up with lipases.

\subsection{Fourier-Transform Infrared Spectroscopy (FTIR)}

FTIR was used to confirm the attachment of enzyme on the surface of the matrix, understanding the nature of bonds involved in the attachment of enzyme and conformational changes of enzyme after immobilization. The appearance of $1700-1600 \mathrm{~cm}^{-1}$ bands indicates the presence of a peptide bond, $\mathrm{C}=\mathrm{O}$ stretching vibration. A broad band observed at a range of 3000 to $3700 \mathrm{~cm}^{-1}$ originated from stretching vibrations of $\mathrm{O}-\mathrm{H}$ and amine $(\mathrm{N}-\mathrm{H})$ bonds. Moreover, the changes of spectra exhibited by the grey shades in Figure 7 indicated the presence of enzyme on the surface area of support.

\subsection{Enzymatic Esterification of Oleic Acid}

The synthesis of ethyl-oleate from oleic acid and ethanol (ratio 1:2) using free and immobilized RoL was evaluated with and without n-hexane. Compared to other organic solvents, n-hexane was selected as the main solvent for the catalytic reaction due to hydrophobicity factor that increased the stability of lipase [15]. Based on Figure 8, it was capable of achieving high conversion of ester with the use of immobilized RoL. With the presence of additive on the support such as hen egg albumin, a higher ester yield was attained of $78 \%$. Other additives such as sodium caseinate contributed to $76 \%$ of ester while CAVAMAX ${ }^{\circledR}$ W6 contributed to $66 \%$ of ester in the enzymatic esterification with n-hexane. Unlike the immobilized RoL, free RoL failed to convert ester in organic media, which leads to low conversion of ester (36\%) as compared to RoL without organic solvent that yielded ester at $59 \%$. Such an observation on ester yields indicates the effect of organic solvent towards enzyme aggregation. To avoid lipase aggregation, immobilized RoL was utilized as the lipase was configured to be more accessible to substrate [16]. 


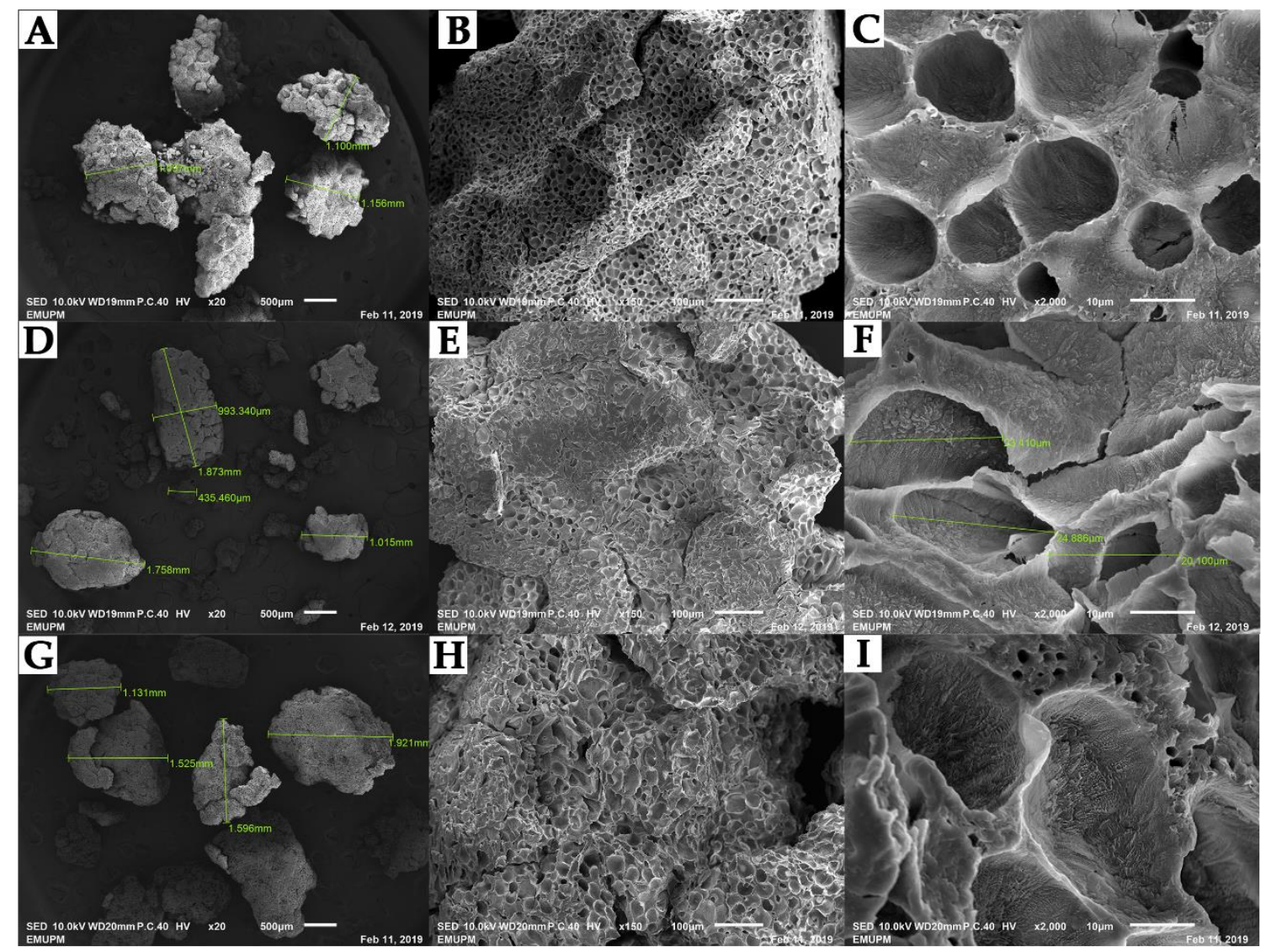

Figure 6. Scanning electron micrograph analysis of empty and immobilized RoL at 20×, 150× and $2000 \times$ magnification. Images (A-C) refer to empty polypropylene support. Images (D-F) refer to immobilized RoL on support without additives. Images (G-I) refer to immobilized RoL on support treated with hen egg albumin.

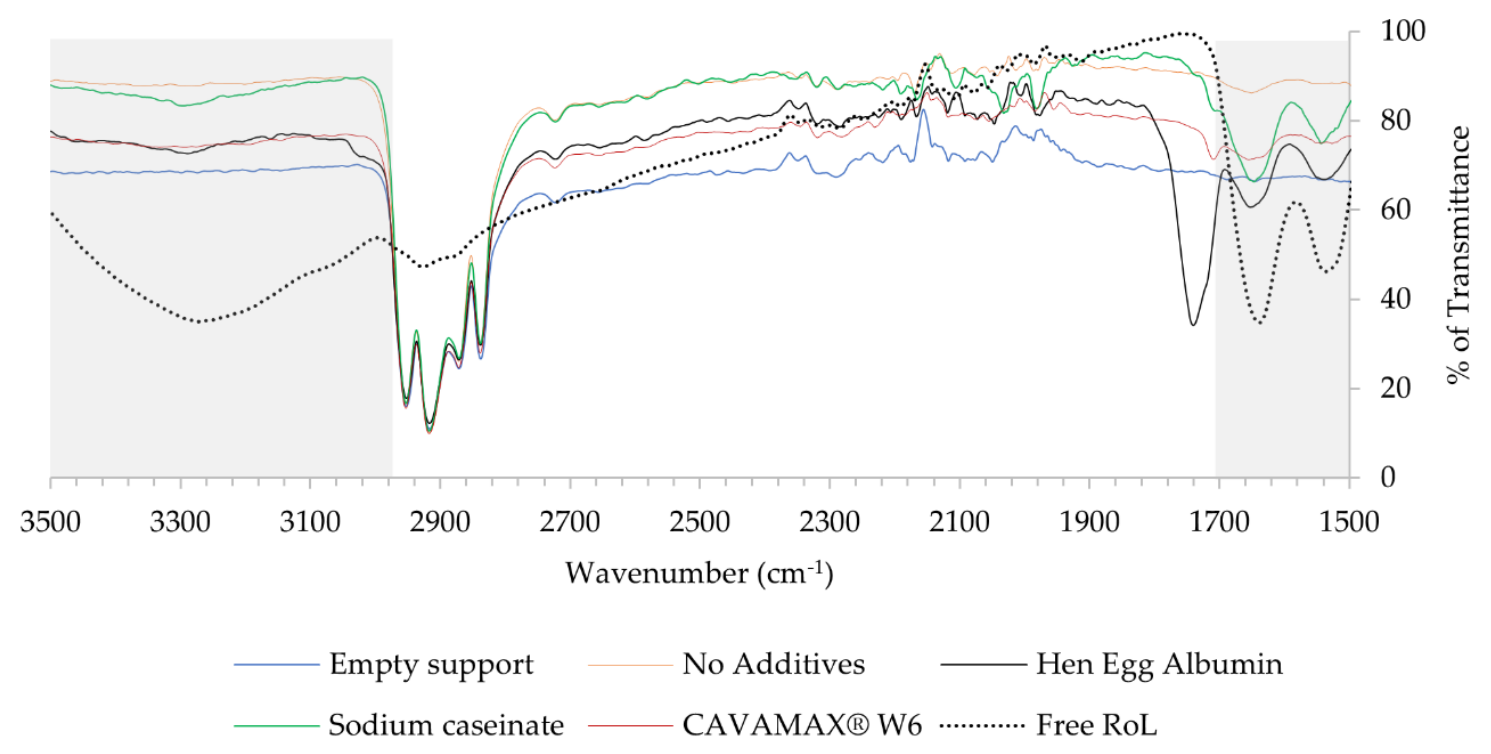

Figure 7. Comparison of infra-red spectra of free RoL, empty polypropylene support and immobilized RoL on polypropylene support with and without additives. The spectral changes (grey shade) harbouring bands from $3500-3000 \mathrm{~cm}^{-1}$ indicating the $\mathrm{N}-\mathrm{H}$ bending and $1700-1600 \mathrm{~cm}^{-1}$ for the stretching of $\mathrm{C}=\mathrm{O}$. 


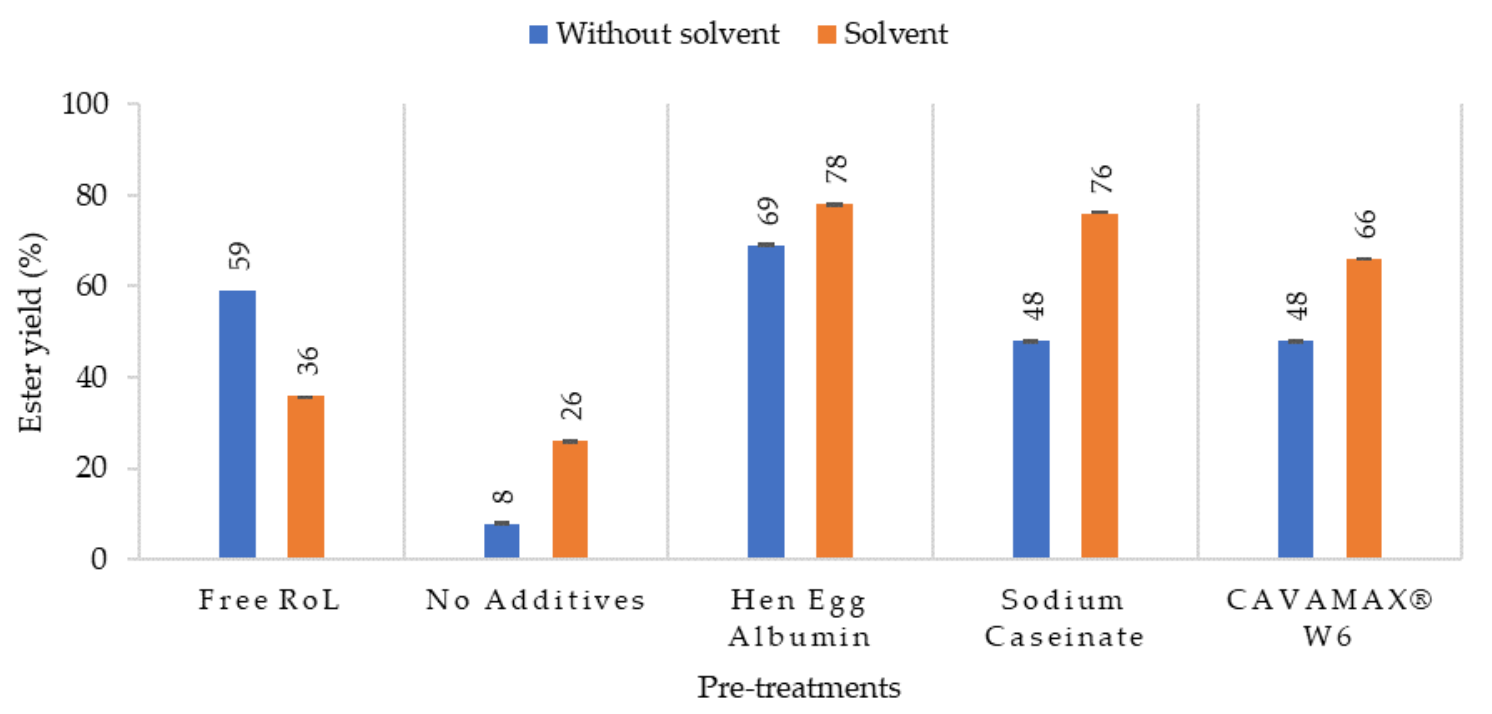

Figure 8. Percentage conversion of ethyl oleate catalyzed by free and immobilized RoL on polypropylene support with and without additives. The esterification was conducted in the hexane and without hexane at $50{ }^{\circ} \mathrm{C}$ with a molar ratio of oleic acid to ethanol that was 1:2.

\section{Discussion}

\subsection{Immobilization of RoL on Polypropylene Support}

Due to the nature of the polypropylene support surface that is nonionic and highly hydrophobic, a monolayer of a nonionic surfactant such as Tween 20 was applied on the surface of supports. The coating increased the membrane hydrophilicity during immobilization. Additives were used to treat the supports and improved the enzyme activity during the esterification reaction. The additives in the likes of hen egg albumin and sodium caseinate have been referred by Bosley and Peilow, 1993 for their use in the adsorption of lipase on hydrophobic support [14]. Both additives were of nonlipase proteins that contained hydrophilic and hydrophobic groups, giving good emulsifying and encapsulation properties [17]. The additives also act as a blocking agent, which minimizes the nonspecific protein binding to the surfaces [18]. The additives adsorption on the support surface was driven by the nonpolar parts of the protein up to a monolayer of the support. Besides the two additives, a polymer additive derived from food-grade alpha-cyclodextrin known as CAVAMAX ${ }^{\circledR}$ W6 (Wacker Chemie AG, Munich, German) comprises six glucose units connected by $\alpha-1,4$ linkages that were capable of forming inclusion complexes was also used in the experiment. Based on the hydrophobic nature of the cyclodextrin cavity, the adsorption and hyperactivation of lipases were executable. The effect of additives on the support for immobilization showed a significant result on improving the yield of immobilized RoL (Figure 1) above immobilization of the same without additives.

Even after immobilization, the leakage of enzyme remained as a limitation for mass transfer. In order to justify this problem, the morphology of polypropylene was examined and based on the findings; the polypropylene has a large internal surface area, showing deep structures within the pores that restrict the accessibility of lipase to the substrate. The loss of catalytic activity after immobilization could also relate to the conformational changes of lipase after immobilization or due to modification of the lipase microenvironment influenced by interactions of the support with the enzyme [11]. According to a previous study, a heterologous Rhizopus oryzae lipase immobilized on MP 1000 and VP OC 1600 had been prepared and used for enzyme leaching [11]. In this study, the immobilized RoL on polypropylene support with additives was configured for esterification on different systems where catalytic performance of the esterification reaction was evaluated to determine the usability of immobilized RoL. 


\subsection{Characterization of RoL Immobilized on Polypropylene Support}

The effect of temperature on hydrolytic activities of free and immobilized RoL was shown in Figure 2. Different to ordinary Rhizopus lipase, having a stable temperature below $50{ }^{\circ} \mathrm{C}$, the optimum temperature for immobilized RoL in the present study was $50{ }^{\circ} \mathrm{C}[19,20]$. The main factor of a declined lipolytic activity at high temperatures was due to the disruption of hydrogen bonds that leads to weak interaction within the lipase molecules. The interaction of lipase with support was governed by hydrophobic interactions [21]. A strong hydrophobic effect on additives had resulted in the open conformation and interfacial activation of lipase during adsorption. Immobilizing RoL on support treated with CAVAMAX ${ }^{\circledR}$ W6 yielded high activity of lipase as compared to other without additives. A similar result was observed in Kolossváry et al. [18] following the high rate of hydrolysis especially of lipid hydrolysis in the presence of $\beta$-cyclodextrin, which acts to crowd the free fatty acid and accelerates lipolysis by reducing product inhibition. The half-life of free RoL was reported to be similar to the half-life of immobilized RoL without additives and immobilized RoL on hen egg albumin-treated support in which the half-life was $2 \mathrm{~h}$. On the contrary, the immobilized RoL on support treated with sodium caseinate and CAVAMAX ${ }^{\circledR}$ W6 showed better stability when exposed to a prolonged incubation at $50{ }^{\circ} \mathrm{C}$.

Duration of storage of the immobilized lipase was significantly evaluated. In the present study, the storage stability of free and immobilized RoL was compared at two temperatures that include $4{ }^{\circ} \mathrm{C}$ and room temperature. A decrease of lipase activity in free RoL was because of conformational change driven by the condition and period of storage. As for the immobilized RoL, aggregation would no longer be a problem as the enzymes were well distributed. Furthermore, rigidification of the enzyme via multiple attachments to the supports will lead to better preservation of enzyme properties under severe conditions [22].

$\mathrm{pH}$ also influenced the functionality of the enzyme. In this study, the $\mathrm{pH}$ properties of immobilized RoL remained at pH 6 in phosphate buffer. In general, immobilization can cause $\mathrm{pH}$ shift depending on the type of the support. When RoL was immobilized in alginate gel beads, the $\mathrm{pH}$ shifted from $\mathrm{pH} 8$ to 7 . The reason of the shifting was due to surface and residual charges on the support, for example polycationic support would result in acidic shift while polyanionic support caused in a shift to more basic $\mathrm{pH}$ values [23]. Therefore, immobilized enzymes are mostly active at broader $\mathrm{pH}$ compared to free enzymes. Figure 5 indicates that the addition of additives improves the activity and stability of RoL over a broader $\mathrm{pH}$ range. A similar outcome to Kharrat et al. [24] showed that the immobilization of RoL had significantly improved its stability at pH 8-8.5.

Visualizing the attachment of enzyme to the surface of support and analyzing its distribution by means of microscopy is time-consuming. However, it is imperative to determine whether the enzyme is located inside the porous structure or adsorbed on the surface of the support. To the advantage of FTIR spectra, the attachment of lipase immobilized on the support could be confirmed. Accordingly, the interactions of lipase to the support were based on the adjustment to the secondary structure of the enzyme. After immobilization, it was shown that the $\mathrm{N}-\mathrm{H}$ bending, $\mathrm{C}=\mathrm{O}$ stretching and $\mathrm{N}-\mathrm{H}$ stretching could be of support to lipases that bind on the surface of the support [25]. Collins et al. [25] also used FTIR to analyze the secondary structure of the immobilized enzyme as part of the characterization of Rhizomucor miehei lipase immobilized in chitosan.

Enzymatic esterification using oleic acid and ethanol at $50{ }^{\circ} \mathrm{C}$ by shaking was conducted via two systems, in which the esterification system includes n-hexane and free n-hexane. A molecular sieve was used as a water adsorbent to prevent a reverse reaction. Similar studies on immobilization had been conducted using CaLB on a polypropylenecoated glass balls [26]. A batch lipase-catalyzed esterification of oleic acid with ethanol in solvent-free systems had also been tested [27] using immobilized Candida sp. [28,29]. In the present study, the production of ethyl oleate had improved with RoL immobilized on a hen egg albumin-treated support in the presence of solvent. A lower retention activity was obtained with RoL immobilized on support treated with hen egg albumin at the 
oil/water interface reaction system due to the size of emulsion droplets which exceed the medium pore diameter of the support. Such an effect leads to a restricted access of lipase to substrate [11].

\section{Materials and Methods}

\subsection{Materials}

Rhizopus oryzae lipase (powder) was obtained from Amano Enzymes, Nagoya, Japan. Polypropylene support was purchased locally from Hynix Asia Sdn Bhd, Selangor, Malaysia. The support particle size was between $200-1500 \mu \mathrm{m}$, and a specific surface area was $0.78 \mathrm{~m}^{2} / \mathrm{g}$ determined by the BET surface area method. The hen egg albumin was purchased from Sigma-Aldrich, Selangor, Malaysia, while sodium caseinate and CAVAMAX ${ }^{\circledR}$ W6 were locally purchased from DKSH, Selangor, Malaysia. CAVAMAX ${ }^{\circledR}$ W6 is a foodgrade alpha-cyclodextrin from Wacker Chemie AG, Munich, Germany where the ringshaped oligosaccharide is produced enzymatically from plant starch. Bertolli olive oil was purchased from a local market in Malaysia.

\subsection{Methods}

\subsection{Immobilization of RoL in Polypropylene Support}

The immobilization procedure with slight modification was carried out according to two granted patents by Bosley and Peilow, 1993 (Patent No. 5232843) and Bosley and Moore, 1998 (Patent No. USOO5773266A). Lipase solution (0.1\%) was added into the treated supports mixture and was stirred for four hours. The supernatant was collected at one-hour intervals. The lipase adsorbed on the supports was filtered and recovered using Buchner funnel vacuum filtration. The wet immobilized lipase was dried using Fluid Bed Dryer TG 200 (Retsch GmbH, Germany) with drying time of $45 \mathrm{~min}$ at $40^{\circ}$ and with airflow of $40 \mathrm{~m}^{3} / \mathrm{h}$. The supernatant obtained from the sampling was checked based on the hydrolytic activity left on the solution. The yield of immobilization was estimated according to the following Equation (1), where t0 is the amount of enzyme present in the buffer solution before the support was added, and $t 4$ is the residual amount of enzyme present in the supernatant after immobilization has completed. The experiment was repeated by replacing hen egg albumin with sodium caseinate and CAVAMAX ${ }^{\circledR}$ W6. The preparation of the support and additives were skipped for experiments involving no additives.

$$
\text { Immobilization yield }(\%)=\frac{(\mathrm{t} 0-\mathrm{t} 4)}{\mathrm{t} 0} \times 100
$$

Loss of hydrolytic activity after immobilization on immobilized RoL was also observed. A total of $10 \mathrm{mg}$ of immobilized RoL was incubated at $50^{\circ} \mathrm{C}$ in $50 \mathrm{mM}$ phosphate buffer under an agitation rate of $200 \mathrm{rpm}$ for $24 \mathrm{~h}$. The activity of immobilized RoL at pre- and postreaction were assayed and the amount of enzyme leached out from the support was calculated according to the Equation (2).

$$
\text { Activity loss }(\%)=\frac{\begin{array}{c}
\text { Initial suspension activity-immobilized enzyme activity- } \\
\text { Supernatant activity after immobilization) }
\end{array}}{\text { (Initial suspension activity) }} \times 100
$$

\subsection{Lipase Activity Determination}

Lipase activity was assayed by a colorimetry method from Kwon and Rhee, 1986 with slight modifications. About $10 \mathrm{mg}$ of immobilized lipase, $2.5 \mathrm{~mL}$ of olive oil emulsion, and $20 \mu \mathrm{L}$ of $20 \mathrm{mM} \mathrm{CaCl}_{2}$ were incubated in a water bath shaker at $50{ }^{\circ} \mathrm{C}$ with agitation rate of $200 \mathrm{rpm}$ for $30 \mathrm{~min}$. After incubation, the enzyme reaction was terminated by adding $1 \mathrm{~mL}$ of $37 \% \mathrm{HCl}(6 \mathrm{~N})$ into the reaction mixture. A total of $5 \mathrm{~mL}$ of isooctane was added, and the mixture was vortexed to mix for 20-30 s each. The mixture was left to settle down for at least $30 \mathrm{~min}$ before separating the upper-layer and transferring the layer into a clean vial containing $1 \mathrm{~mL}$ of $5 \%(w / v)$ copper (II) pyridine. The mixture was vortexed for the second time and left to settle at room temperature until a green-colored lysate appeared at the first 
layer. Using the green-colored lysate, lipase activity was measured spectrophotometrically at $715 \mathrm{~nm}$ and standard curve oleic acid was used to quantify said lipase activity. One unit of lipase activity was defined as the rate of $1 \mu$ mole fatty acid released per minute [30].

\subsection{Characterization of Immobilized RoL}

\subsubsection{Effect of Temperature on Enzyme Activity}

The nonimmobilized and immobilized lipase were incubated at temperature range at $30{ }^{\circ} \mathrm{C}$ to $70{ }^{\circ} \mathrm{C}$ with $10{ }^{\circ} \mathrm{C}$ intervals for $30 \mathrm{~min}$. The enzyme activity was assayed, as described at Section 4.2.

\subsubsection{Effect of Temperature on Enzyme Stability}

The nonimmobilized and immobilized lipase samples were incubated at $50{ }^{\circ} \mathrm{C}$ for $1-5 \mathrm{~h}$ before the lipase assay. The residual enzyme activity was assayed, as described previously. For storage stability, the immobilized enzyme was stored at $4{ }^{\circ} \mathrm{C}$ and room temperature, and the residual enzyme activity was assayed at monthly intervals.

\subsubsection{Effect of $\mathrm{pH}$ on Enzyme Activity}

The effect of $\mathrm{pH}$ on immobilized RoL activity was evaluated at $\mathrm{pH} 4$ to 9. Lipase activity was assayed using buffers with different $\mathrm{pH}$ that include $50 \mathrm{mM}$ sodium citrate buffer ( $\mathrm{pH} 4-5), 50 \mathrm{mM}$ potassium phosphate buffer (pH 6-8), and $50 \mathrm{mM}$ Tris-HCl buffer (pH 8-9).

\subsubsection{Scanning of Electron Microscopy}

The empty and immobilized lipase morphology was investigated using Scanning Electron Microscopy (SEM). Analysis was carried out using JSM-IT200 InTouchScope ${ }^{\mathrm{TM}}$ (JEOL, Japan). The supports were mounted on a specimen stub and dried overnight in the oven $\left(40^{\circ} \mathrm{C}\right)$ to remove the sample's moisture. Then, the sample was coated with gold before scanned by SEM. The morphologies and shapes of support were observed at various magnifications $(20 \times, 500 \times$, and $2000 \times)$.

\subsubsection{Fourier-Transform Infrared Spectroscopy}

The physical characteristics of free lipase, empty supports, additives and immobilized lipase were determined by the Fourier Transform Infrared Spectroscopy Attenuated Total Reflection (FTIR-ATR) test method. Analysis was carried out at a resolution of $4 \mathrm{~cm}^{-1}$ between 4000 and $450 \mathrm{~cm}^{-1}$ with an average of 32 scans using the FT-IR spectrometer Nicolet 6700, Thermo Scientific, Waltham, MA, USA.

\subsection{Enzymatic Esterification of Oleic Acid}

Enzymatic esterification of oleic acid by immobilized lipase was conducted according to the modified Cea et al. 2019 method. The enzymatic esterification reaction was carried out in screw-capped bottles containing oleic acid $(1.0 \mathrm{mmol})$, ethanol $(2.0 \mathrm{mmol})$ and free or immobilized lipase ( $5 \mathrm{wt} \%$ based on oleic acid). The reaction was carried out with or without solvent system $(1.0 \mathrm{~mL}$ hexane $)$ at $50{ }^{\circ} \mathrm{C}$, by constant shaking at $200 \mathrm{rpm}$ for $18 \mathrm{~h}$. The reaction was terminated by dilution with $2.0 \mathrm{~mL}$ of ethanol: acetone $(50: 50 \mathrm{v} / \mathrm{v})$. The remaining free fatty acids in the reaction mixture were determined by titration with $0.1 \mathrm{M} \mathrm{NaOH}$ using phenolphthalein as an indicator. For blank determination, the reaction mixture without enzyme was used. The yield of ester, ethyl oleate was expressed as a percentage of converted oleic acid compared to the total initial fatty acid content in the reaction mixture. The conversion of ester was expressed as percentage conversion (\%) according to the following Equation (3) [31-33]:

$$
\text { Conversion of ester }(\%)=\frac{\text { Volume of } \mathrm{NaOH}(\text { Control }- \text { With enzyme })}{\text { Volume of } \mathrm{NaOH}(\text { Control })} \times 100
$$




\section{Conclusions}

This study has shown that the immobilization of RoL on support treated with additives was capable of further enhancing the activity and stability of immobilized lipase. According to the catalytic activity of immobilized RoL on support treated with CAVAMAX ${ }^{\circledR}$ W6, the enzyme was found to be more stable at $50{ }^{\circ} \mathrm{C}$ and storage stability at $4{ }^{\circ} \mathrm{C}$. The immobilized enzyme had an optimum temperature and $\mathrm{pH}$ preference at $50^{\circ} \mathrm{C}$ and $\mathrm{pH} 6$, respectively. Overall, the immobilization of enzyme on porous support with additives had successfully enhanced the biophysical characteristics of immobilized enzyme with minimal loss in hydrolytic activity. In addition, the oleic acid esterification with RoL immobilized in support treated with hen egg albumin leads to highest ester yield compared to free-RoL and immobilized RoL on support with other additives. Therefore, the high ester yield was a proof of evidence for the efficiency of immobilized RoL in which the addition of hen egg albumin to the support was the main reason of improvement.

Supplementary Materials: The following are available online at https:/ / www.mdpi.com/2073-434 $4 / 11 / 3 / 303 / s 1$.

Author Contributions: F.S. conceived and designed the experiments, performed the experiments, analyzed the data, contributed reagents/materials/analysis tools, prepared figures and/or tables, authored or reviewed drafts of the paper, approved the final draft. N.F.M. conceived and designed the experiments, authored or reviewed drafts of the paper, approved the final draft. M.S.M.A. analyzed the data, approved the final draft. R.N.Z.R.A.R. conceived and designed the experiments, analyzed the data, contributed reagents/materials/analysis tools, authored or reviewed drafts of the paper, approved the final draft. All authors have read and agreed to the published version of the manuscript.

Funding: This research was supported by the Ministry of Science, Technology \& Innovation, Malaysia (ScienceFund: 02-01-04-SF2460) and the APC was funded by Universiti Putra Malaysia.

Data Availability Statement: Data is contained within the article or supplementary material.

Conflicts of Interest: The authors declare there are no competing interests.

\section{References}

1. Abaházi, E.; Boros, Z.; Poppe, L. Additives Enhancing the Catalytic Properties of Lipase from Burkholderia cepacia Immobilized on Mixed-Function-Grafted Mesoporous Silica Gel. Molecules 2014, 19, 9818-9837. [CrossRef]

2. Palomo, J.M.; Ortiz, C.; Fuentes, M.; Fernandez-Lorente, G.; Guisan, J.M.; Fernandez-Lafuente, R. Use of immobilized lipases for lipase purification via specific lipase-lipase interactions. J. Chromatogr. A 2004, 1038, 267-273. [CrossRef]

3. Sheldon, R.A.; van Pelt, S. Enzyme immobilisation in biocatalysis: Why, what and how. Chem. Soc. Rev. 2013, 42, 6223-6235. [CrossRef]

4. Palomo, J.M.; Filice, M.; Romero, O.; Guisan, J.M. Improving Lipase Activity by Immobilization and Post-immobilization Strategies. Methods Mol. Biol. 2013, 1051, 255-273. [CrossRef] [PubMed]

5. Ramachandran, P.; Narayanan, G.K.; Gandhi, S.; Sethuraman, S.; Krishnan, U.M. Rhizopus oryzae Lipase Immobilized on Hierarchical Mesoporous Silica Supports for Transesterification of Rice Bran Oil. Appl. Biochem. Biotechnol. 2015, 175, $2332-2346$. [CrossRef] [PubMed]

6. Tufvesson, P.; Törnvall, U.; Carvalho, J.; Karlsson, A.J.; Hatti-Kaul, R. Towards a cost-effective immobilized lipase for the synthesis of specialty chemicals. J. Mol. Catal. B Enzym. 2011, 68, 200-205. [CrossRef]

7. Manoel, E.A.; Ribeiro, M.F.; dos Santos, J.C.; Coelho, M.A.Z.; Simas, A.B.; Fernandez-Lafuente, R.; Freire, D.M. Accurel MP 1000 as a support for the immobilization of lipase from Burkholderia cepacia: Application to the kinetic resolution of myo-inositol derivatives. Process. Biochem. 2015, 50, 1557-1564. [CrossRef]

8. Salis, A.; Sanjust, E.; Solinas, V.; Monduzzi, M. Characterisation of Accurel MP1004 polypropylene powder and its use as a support for lipase immobilisation. J. Mol. Catal. B Enzym. 2003, 24, 75-82. [CrossRef]

9. Foresti, M.; Ferreira, M. Ethanol pretreatment effect and particle diameter issues on the adsorption of Candida rugosa lipase onto polypropylene powder. Appl. Surf. Sci. 2004, 238, 86-90. [CrossRef]

10. Salis, A.; Sanjust, E.; Solinas, V.; Monduzzi, M. Commercial lipase immobilization on Accurel MP 1004 porous polypropylene. Biocatal. Biotransformation 2005, 23, 381-386. [CrossRef]

11. Tecelão, C.; Guillén, M.; Valero, F.; Ferreira-Dias, S. Immobilized heterologous Rhizopus oryzae lipase: A feasible biocatalyst for the production of human milk fat substitutes. Biochem. Eng. J. 2012, 67, 104-110. [CrossRef] 
12. Cao, H.; Jiang, Y.; Zhang, H.; Nie, K.; Lei, M.; Deng, L.; Wang, F.; Tan, T. Enhancement of methanol resistance of Yarrowia lipolytica lipase 2 using $\beta$-cyclodextrin as an additive: Insights from experiments and molecular dynamics simulation. Enzym. Microb. Technol. 2017, 96, 157-162. [CrossRef]

13. Bolivar, J.M.; Batalla, P.; Mateo, C.; Carrascosa, A.V.; Pessela, B.C.; Guisán, J.M. Selective adsorption of small proteins on large-pore anion exchangers coated with medium size proteins. Colloids Surf. B Biointerfaces 2010, 78, 140-145. [CrossRef]

14. Matijasevic, B.; Banhart, J. Improvement of aluminium foam technology by tailoring of blowing agent. Scr. Mater. 2006, 54, 503-508. [CrossRef]

15. Madalozzo, A.D.; Muniz, L.S.; Baron, A.M.; Piovan, L.; Mitchell, D.A.; Krieger, N. Characterization of an immobilized recombinant lipase from Rhizopus oryzae: Synthesis of ethyl-oleate. Biocatal. Agric. Biotechnol. 2014, 3, 13-19. [CrossRef]

16. Kartal, F. Enhanced esterification activity through interfacial activation and cross-linked immobilization mechanism of Rhizopus oryzaelipase in a nonaqueous medium. Biotechnol. Prog. 2016, 32, 899-904. [CrossRef]

17. Chew, S.C.; Tan, C.P.; Nyam, K.L. Effect of Gum Arabic, $\beta$-Cyclodextrin, and Sodium Caseinate as Encapsulating Agent on the Oxidative Stability and Bioactive Compounds of Spray-Dried Kenaf Seed Oil. J. Food Sci. 2018, 83, 2288-2294. [CrossRef] [PubMed]

18. Jeyachandran, Y.L.; Mielczarski, E.; Rai, B.; Mielczarski, J.A. Quantitative and Qualitative Evaluation of Adsorption/Desorption of Bovine Serum Albumin on Hydrophilic and Hydrophobic Surfaces. Langmuir 2009, 25, 11614-11620. [CrossRef] [PubMed]

19. Razak, C.; Salleh, A.; Musani, R.; Samad, M.; Basri, M. Some characteristics of lipases from thermophilic fungi isolated from palm oil mill effluent. J. Mol. Catal. B Enzym. 1997, 3, 153-159. [CrossRef]

20. Yu, X.-W.; Xu, Y.; Xiao, R. Lipases from the genus Rhizopus: Characteristics, expression, protein engineering and application. Prog. Lipid Res. 2016, 64, 57-68. [CrossRef]

21. Gitlesen, T.; Bauer, M.; Adlercreutz, P. Adsorption of lipase on polypropylene powder. Biochim. Biophys. Acta Lipids Lipid Metab. 1997, 1345, 188-196. [CrossRef]

22. Rodrigues, R.C.; Ortiz, C.; Berenguer-Murcia, Á.; Torres, R.; Fernández-Lafuente, R. Modifying enzyme activity and selectivity by immobilization. Chem. Soc. Rev. 2013, 42, 6290-6307. [CrossRef]

23. Ghattas, N.; Abidi, F.; Galai, S.; Marzouki, M.N.; Ben, S.A. Monoolein production by triglycerides hydrolysis using immobilized Rhizopus oryzae lipase. Int. J. Biol. Macromol. 2014, 68, 1-6. [CrossRef]

24. Kharrat, N.; Ben, A.Y.; Marzouk, S.; Gargouri, Y.-T.; Karra-Châabouni, M. Immobilization of Rhizopus oryzae lipase on silica aerogels by adsorption: Comparison with the free enzyme. Process. Biochem. 2011, 46, 1083-1089. [CrossRef]

25. Collins, S.E.; Lassalle, V.; Ferreira, M.L. FTIR-ATR characterization of free Rhizomucor meihei lipase (RML), Lipozyme RM IM and chitosan-immobilized RML. J. Mol. Catal. B Enzym. 2011, 72, 220-228. [CrossRef]

26. Foresti, M.; Ferreira, M. Analysis of the interaction of lipases with polypropylene of different structure and polypropylenemodified glass surface. Colloids Surf. A Physicochem. Eng. Asp. 2007, 294, 147-155. [CrossRef]

27. Sandoval, G.; Condoret, J.S.; Monsan, P.; Marty, A. Esterification by immobilized lipase in solvent-free media: Kinetic and thermodynamic arguments. Biotechnol. Bioeng. 2002, 78, 313-320. [CrossRef] [PubMed]

28. Trubiano, G.; Borio, D.; Ferreira, M.L. Ethyl Oleate Synthesis Using Candida rugosa Lipase in a Solvent-Free System. Role of Hydrophobic Interactions. Biomacromolecules 2004, 5, 1832-1840. [CrossRef]

29. Li, W.-N.; Chen, B.-Q.; Tan, T.-W. Esterification Synthesis of Ethyl Oleate in Solvent-Free System Catalyzed by Lipase Membrane from Fermentation Broth. Appl. Biochem. Biotechnol. 2011, 163, 102-111. [CrossRef]

30. Bosley, J.A.; Moore, S.R. Immobilized Lipases on a Dry, Porous Particulate Hydrophobic Support and Containing a Non-Ionic Surfactant. U.S. Patent USOO5773266A, 30 June 1998.

31. Kwon, D.Y.; Rhee, J.S. A simple and rapid colorimetric method for determination of free fatty acids for lipase assay. J. Am. Oil Chem. Soc. 1986, 63, 89-92. [CrossRef]

32. Cea, M.; González, M.E.; Abarzúa, M.; Navia, R. Enzymatic esterification of oleic acid by Candida rugosa lipase immobilized onto biochar. J. Environ. Manag. 2019, 242, 171-177. [CrossRef] [PubMed]

33. Musa, N.; Latip, W.; Rahman, R.N.Z.A.; Salleh, A.B.; Ali, M.S.M. Immobilization of an Antarctic Pseudomonas AMS8 Lipase for Low Temperature Ethyl Hexanoate Synthesis. Catalysts 2018, 8, 234. [CrossRef] 